\title{
Cardiovascular Risk Factors in the Population of Jamapa
}

\author{
María Dora Portilla Cárdenas ${ }^{1}$, Roberto E Castañeda Hernández ${ }^{1}$, Laura M Bolívar Duarte ${ }^{1}$, Adhali Rodriguez \\ Ruiz $^{1}$, Mara Elisa Salazar Calderón ${ }^{2}$, Alfonso Alexander Aguilera ${ }^{1}$ and Rosa Amelia Deschamps Lago ${ }^{1 *}$
}

${ }^{1}$ Facultad de Bioanálisis, Universidad Veracruzana, Mexico

${ }^{2}$ Facultad de Medicina Veterinaria y Zootecnia, Universidad Veracruzana, Mexico

*Corresponding author: Rosa Amelia Deschamps Lago, Facultad de Bioanalisis, Universidad Veracruzana, Mexico

\begin{abstract}
Introduction: Cardiovascular diseases are a group of pathologies that affect the heart and blood vessels. They represent the leading cause of death in the world and also in Mexico. Timely identification of risk factors for these diseases is important because it allows for better guidance on activities carried out by health authorities to reduce the number of avoidable deaths. Numerous studies have been conducted in this regard, however, most of them have focused on large urban communities, which makes necessary to cover otear type of populations.
\end{abstract}

Objective: To identify the presence of cardiovascular risk factors (CRF) in the population of Jamapa, Veracruz, Mexico.

Material and Methods: A descriptive and cross-sectional study was conducted in 81 patients of both genders, aged 20 years or older. Glycemia, lipid profile, insulinemia and anthropometric variables were measured, insulin resistance using the HOMA-IR index was estimated and a survey was applied to register history of cardiovascular disease and lifestyle.

Results: The CRF found were overweight/obesity (74.07\%), sedentaryism (74.07\%), abdominal obesity (55.56\%) significantly higher in women $\chi 2(\mathrm{p}<0.05)$, hypertriglyceridemia $(50.6 \%)$, hypercholesterolemia $(48.14 \%)$, decreased levels of c-HDL (42.00\%), diabetics (38.27\%) and hypertensive (34.57\%). 100\% of patients had at least one cardiovascular risk factor, and a maximum of nine risk factors were found in $2.5 \%$ of the total population.

Conclusion: A high prevalence of cardiovascular risk factors was observed in the population studied, and a high tendency to associate among them, denoting the need to develop strategies to address health problems in these communities.

Keywords: Cardiovascular diseases; Frequency; Risk factors; Jamapa; Veracruz

\section{Introduction}

Cardiovascular diseases (CVD) are a group of disorders of the heart and blood vessels. These pathologies occur mainly as a result of a blockage of the vessels which prevents normal blood flow affecting various organs and tissues. Lipid deposits in the inner walls of vessels are the most common cause of obstruction by significantly reducing their diameter as well as their flexibility. This hardening of the arteries is known as atherosclerosis. Narrowing vessels increases the likelihood of blood clots, further contributing to vascular obstruction and decreased blog supply with subsequent organ injury [1]. The study of these diseases is of great importance today as they constitute the number one cause of mortality in the world. In 2016, 17.9 million people died of these diseases worldwide, approximately 7.4 million were due to coronary heart disease, and 6.7 million to strokes. It is projected that by 2030 almost 23.6 million people will die from some cardiovascular disease and these pathologies will continue to be the leading cause of death worldwide [2,3]. In Mexico, 25.5\% of deaths in people aged $<60$ years are related to chronic noncommunicable diseases, specifically $19.9 \%$ corresponding to cardiovascular disease according to the National Institute of Statistic and Geography 2016, INEGI 2016, Mexico [4,5].

There are risk factors that can cause these diseases to develop, they are calle Cardiovascular Risk Factors (CRF), they can be biological, environmental, behavioral, sociocultural, economic; some are modifiable, including diabetes, hypertension, obesity and some lifestyle habits such as sedentarism and smoking; others 
cannot be modified as age, gender and family history. In many cases the sum of them increases their isolated effect producing a phenomenon of interaction or synergy [6]. Obviaos manifestations of cardiovascular disease, such as heart attack, stroke or others, usually appear in adulthood, however, risk factors are usually present from childhood or adolescence, terere the importance of detecting them early [7]. There are numerous studies on the prevalence of CRF, however, most of them have been conducted in large urban communities in the world, Latin America as well as in Mexico [8-10]. In this sense, it is necessary to cover different types of populations, especially those devoid of timely detection and which are prone to various health problems related to feeding conditions, economy, hygiene, housing, among others. The above justified the completion of the present study that aimed to identify the presence of cardiovascular risk factors (CRF) in the population of Jamapa, Veracruz, Mexico. Jamapa Municipality is located in the state of Veracruz, Mexico. It covers an area of $132.4 \mathrm{Km}^{2}$, and borders the north with the municipalities of Manlio Fabio Altamirano and Medellín; the east with Medellin; the south with the municipalities of Medellin and Cotaxtla; the west with Cotaxtla and Manlio Fabio Altamirano. It consists of 39 towns, 1 urban and 38 rural, the head town is Jamapa with 3,928 inhabitamos (Figure 1) [11].

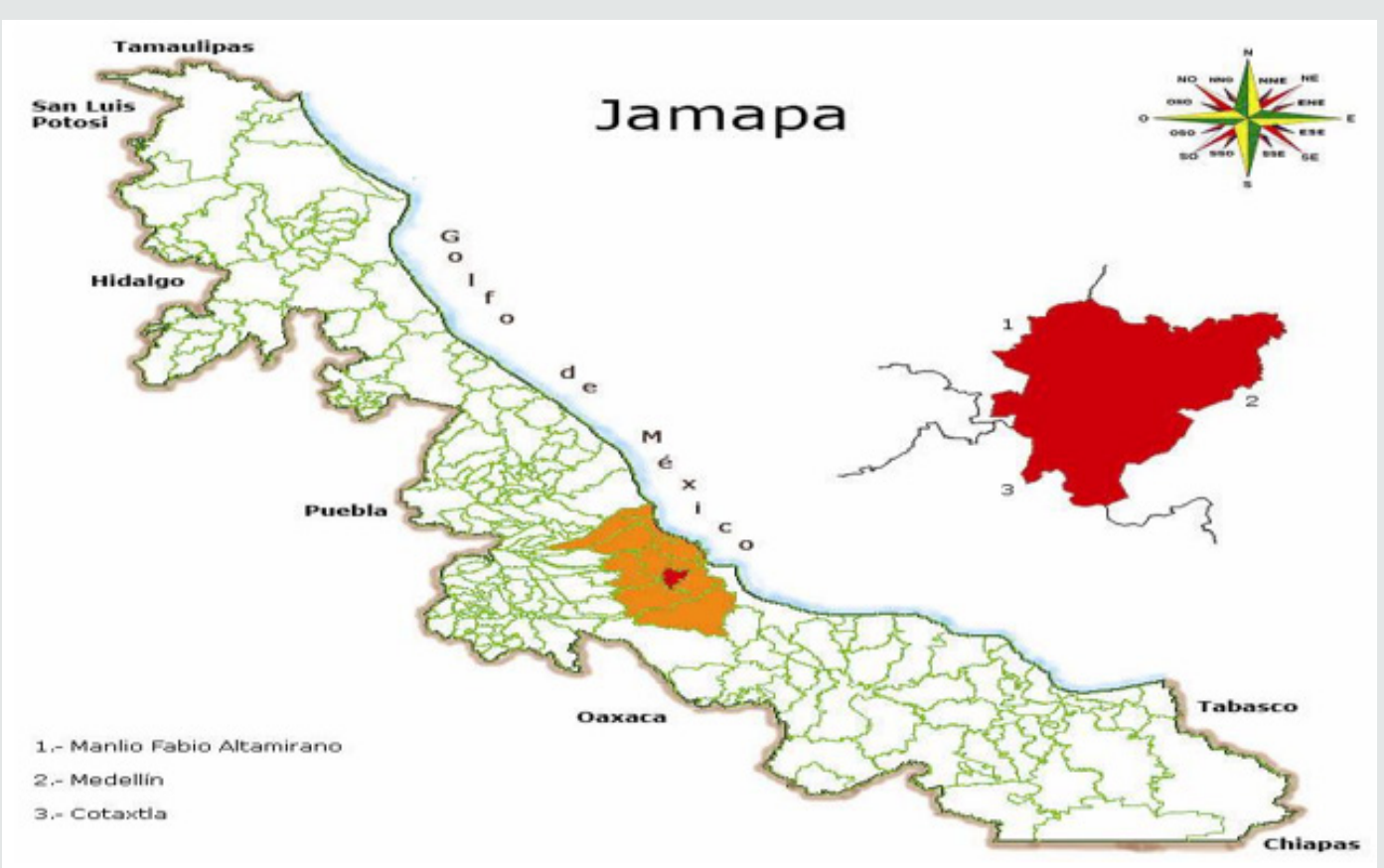

Figure 1: Geographic location of Jamapa, Veracruz, México [11].

\section{Material and Methods}

As part of a health brigade conducted by the Faculty of Bioanalysis, Region Veracruz, of the Universidad Veracruzana, a visit was made to the community of Jamapa, Veracruz, in June 2019, with the aim of detecting risk factors of cardiovascular diseases in its inhabitants. The descriptive and cross-sectional study included 81 subjects aged 20 years and older of both sexes. A survey was conducted to learn history of cardiovascular disease and lifestyle, anthropometric measurements were performed, biochemical blood tests were analyzed and the results were analyzed statistically.

\section{Collection of information}

By applying a survey with dichotomous and some open questions, information was obtained of variables such as age, sex, family and personal history of diabetes, dyslipidemias and cardiovascular disease, as well as behavioral habits such as smoking and physical activity.

\section{Anthropometric measures}

Measurement of height, weight, waist circumference and blood pressure was conducted in accordance with the manual of procedures: "Clinical and Anthropometric Measurements in the Adult and Elderly" of the Ministry of Health, Mexico. Calculation of the Body Mass Index (BMI) was made with the following formula,

$\mathrm{BMI}=$ weight $(\mathrm{Kg}) /[\text { height }(\mathrm{m})]^{2}[12]$.

\section{Serum biochemical tests}

After a 12-14 hour fast, blood samples were taken from the subjects, and processed in the laboratory of the Faculty of Bioanalysis, region Veracruz, Universidad Veracruzana. Glucose, total cholesterol, high-density lipoprotein cholesterol (HDL) and triglyceride were measured using colorimetric enzyme methods (Spinreact, Girona, Spain). LDL cholesterol was calculated using

Friedewald's equation: $\mathrm{LDL}^{\mathrm{c}}=$ Total Cholesterol-HDL ${ }^{\mathrm{c}}-(\mathrm{TG} / 5)$ [13]

Insulin determination was performed using an enzyme immunoassay method (Mexlab, Mexico). Insulin resistance was calculated with the HOMA-IR index (Homeostasis Model Assesment), proposed by Matthews using the formula: HOMA-IR= fasting insulin $(\mu \mathrm{UI} / \mathrm{ml}) *$ fasting glucose $(\mathrm{mg} / \mathrm{dL}) / 405->[14]$. 


\section{Clinical definitions/cut-off points}

The criteria used to define cut-off points for risk factors were as follows: Age: in men $\geq 45$ years, and in women $\geq 55$ years. Family history: Subjects with a first-degree male family member (parent or sibling) who suffered a heart attack or other cardiovascular event before age 55 or a first-degree female relative (mother or sister) before age 65 . Total serum cholesterol: $\geq 200 \mathrm{mg} / \mathrm{dL},{ }^{c-L D L}$ : $\geq 130 \mathrm{mg} / \mathrm{dl}$, c-HDL: $<40 \mathrm{mg} / \mathrm{dl}$, Triglycerides: $\geq 150 \mathrm{mg} / \mathrm{dl}$. Blood pressure: systolic $\geq 140 \mathrm{mmHg}$ and a diastolic $\geq 90 \mathrm{mmHg}$, or the indication of current antihypertensive treatment. All these criteria in accordance with the National Cholesterol Education Program (NCEP) Adult Treatment Panel III (ATP-III) [15]. As suggested by WHO, overweight/obesity was considered with a body mass index (BMI $\mathrm{Kg} / \mathrm{m}^{2}$ ), $\geq 25$ for overweight and $\geq 30$ for obesity [16]. Insulin resistance (HOMA-IR): $>3$. Sedentary, $<150$ minutes of moderate physical activity weekly [17]. Smoking, consumption of any tobacco product daily or occasional [18]. Finally, the diagnostic criterion of Diabetes mellitus following the recommendation of the American Diabetes Association (ADA) was fasting glucose $126 \mathrm{mg} / \mathrm{dL}$ or personal history of the disease [19].

\section{Statistical method}

Risk factors were dichotomized in the form of presence versus absence. Categorical variables have been presented as percentage. Comparison of proportions was made between groups (men and women) using the Pearson Square Chi test. Continuous variables with normal distribution were presented as mean (standard deviation), non-normal variables were reported as median. The assumption of normality was assessed through the KolmogorovSmirnov tests and the homogeneity of variances between groups by the Levene test. Means of two continuous normally distributed variables were compared using the Student's t test, and MannWhitney when the distribution was not normal. The statistical significance level was set to $\mathrm{p}<0.05$ and $95 \%$ confidence intervals were calculated. The IBM SPSS version 22 program was used for statistical analysis.

\section{Results}

A total of 81 patients from the municipality of Jamapa, Veracruz, Mexico were studied; 20 (24.7\%) were male and 61 (75.3\%) were female. The average age was $49.04 \pm 15.86$ years. The proportion of subjects presenting age of risk for cardiovascular disease was 40.74\%, 74.07\% showed overweight/obesity, 55.56\% abdominal obesity, $74.07 \%$ sedentaryism, $50.6 \%$ hypertriglyceridemia, 48.14\% hypercholesterolemia, 42.00\% decreased HDL levels. Diabetics accounted for $38.27 \%$ and hypertensives $34.57 \%$. By sex, $60 \%$ of men were at risk age against $34.42 \%$ of women, with significant difference $x 2(p<0.05)$. It also highlights with significant difference the higher frequency of abdominal obesity among women in relation to men $\chi 2(\mathrm{p}<0.05)$, for the other variables studied, the Parsons Chi-saquead test showed that there is no significant difference between the proporciona of men and women ( $p>0.05$ ) (Table 1). Serum insulin levels and HOMA-IR index calculation were estimated in 47 patients, 12 men and 35 women, who had any of the following parameters established as diagnostic criteria for Metabolic Syndrome by WHO: Diabetes mellitus, BMI $\geq 30$, hypertriglyceridemia and decreased levels of c-HDL. It was found that $6(12.8 \%)$ of the patients studied presented hiperinsulinism. By sex, $3(25 \%)$ were men and $3(8.6 \%)$ women. In relation to HOMA-IR, it was observed that $28(34.57 \%)$ subjects had an index greater than 3 , denoting the existence of insulin resistance.

Table 1: Cardiovascular risk in total population and according to sex. p: comparison of male and female groups ( $x^{2}$ test).

\begin{tabular}{|c|c|c|c|c|c|c|c|}
\hline & \multicolumn{2}{|c|}{ Total De La Poblaciónes (81) } & \multicolumn{2}{|c|}{ Men (20) } & \multicolumn{3}{|c|}{ Women (61) } \\
\hline & n & $\%$ & $\mathbf{n}$ & $\%$ & $\mathbf{n}$ & $\%$ & $\mathbf{p}$ \\
\hline Age & 33 & 40.74 & 12 & 60 & 21 & 34.42 & 0.043 \\
\hline Family history of CVD & 20 & 24.69 & 4 & 20 & 16 & 26.23 & 0.793 \\
\hline Total cholesterol k $200 \mathrm{mg} / \mathrm{dL}$ & 39 & 48.14 & 8 & 40 & 31 & 50.82 & 0.401 \\
\hline c-LDL k 130mg/dL & 32 & 39.5 & 4 & 20 & 26 & 42.62 & 0.064 \\
\hline c-HDL $<40$ nagidl & 34 & 42 & 6 & 30 & 30 & 49.18 & 0.143 \\
\hline Triglicerydes k 150mg/dL & 41 & 50.61 & 10 & 50 & 31 & 50.82 & 0.949 \\
\hline Diabetes mellitus & 31 & 38.27 & 8 & 40 & 23 & 37.7 & 0.372 \\
\hline Overweight/Obesity (BMI) & 60 & 74.07 & 14 & 70 & 46 & 75.41 & 1 \\
\hline Abdominal Obesity & 45 & 55.56 & 7 & 35 & 38 & 62.3 & 0.039 \\
\hline Hypertension & 28 & 34.57 & 5 & 25 & 23 & 37.1 & 0.363 \\
\hline Sedentarism & 60 & 74.07 & 15 & 75 & 45 & 73.77 & 0.913 \\
\hline Smoking & 6 & 7.41 & 3 & 15 & 3 & 15 & 0.157 \\
\hline Smokers & 5 & 6.17 & 2 & 10 & 3 & 15 & \\
\hline Ex-smokers & 1 & 1.23 & 1 & 5 & 0 & 0 & \\
\hline
\end{tabular}

$100 \%$ of the subjects showed at least one cardiovascular risk factor. The highest percentage (18.5\%) was observed in the group of patients with 5 risk factors, followed by the group with 3 factors
(14.8\%). A maximum of nine risk factors were observed in $2.5 \%$ of the total population. Figure 2 Means and medians of biochemical parameters are presented (Table 2). For total cholesterol, the mean 
was $204 \pm 52.41 \mathrm{mg} / \mathrm{dL}$ in total population, according to gender, for women it was $204.4 \pm 45.9 \mathrm{mg} / \mathrm{dL}$, and $203 \pm 70 \mathrm{mg} / \mathrm{dL}$ in men. The Student's t test showed no significant difference between men and women (t.101, p.920). In total population a median of $41 \mathrm{mg} / \mathrm{dL}$ was observed in HDL cholesterol. By sex, it was $42 \mathrm{mg} / \mathrm{dL}$ in women and $38.5 \mathrm{mg} / \mathrm{dL}$ in men; with no significant difference between medians (U-515.5; p-300). LDL cholesterol mean was $124.66 \pm 39.89 \mathrm{mg} / \mathrm{dL}$ in total population, $126.63 \pm 37.97$ in women and $118.65 \pm 45.79 \mathrm{mg} / \mathrm{dL}$ in men. Student's t-test revealed no significant difference between men and women (t.775, p.441). Regarding Triglycerides, a median of
$153 \mathrm{mg} / \mathrm{dL}$ was obtained in total population; by sex, it was $153 \mathrm{mg} /$ $\mathrm{dL}$ in women, and $148.5 \mathrm{mg} / \mathrm{dL}$ in men, with no significant difference between the medians of both groups. For serum glucose, a median of $87.0 \mathrm{mg} / \mathrm{dL}$ was observed in the total of patients studied. Looking at both sexes, in women it was $87.0 \mathrm{mg} / \mathrm{dL}$, and in men $85 \mathrm{mg} / \mathrm{dL}$ with no significant difference between them (U Mann-Whitney 581; p-0.751). Finally, with regard to serum insulin, a median of $12 \mu \mathrm{lU} /$ $\mathrm{ml}$ was obtained. Comparing sexes, it was $13 \mu \mathrm{lU} / \mathrm{ml}$ in women and $9.5 \mu \mathrm{lU} / \mathrm{ml}$ in men, not having a significant difference between the two (U Mann-Whitney 176; p.0.406).

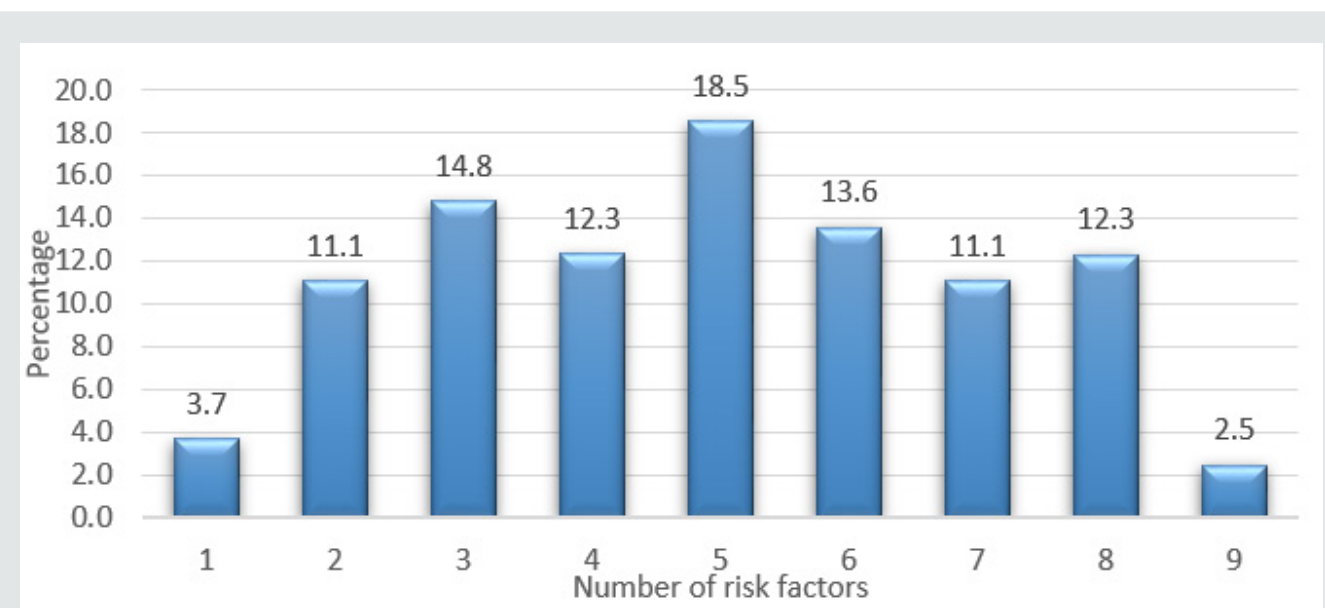

Figure 2: Percentage of patients with one or more cardiovascular risk factor.

Table 2: Lipid, glucose and insulin values in the total population and according to sex. p: comparison of male and female groups Student's t test and Mann-Whitney U test $){ }^{*} \mathrm{t}(\mathrm{p}>0.05) \mathrm{NS}{ }^{*} \mathrm{U}(\mathrm{p}>0.05)$ NS TC-total colesterol, HDL ${ }^{\mathrm{c}}$. HDL cholesterol, LDLc- LDL cholesterol, TG-triglicerydes, GLU-glucose,l-insulina.

\begin{tabular}{|c|c|c|c|c|}
\hline Parameter & In Total Population & Men & Women & P \\
\hline TCmg/d1 & $204 \pm 52.41$ & $203.05 \pm 70.0$ & $204.43 \pm 45.93$ & $0.920^{*}$ \\
\hline HDL-cmg/d1 & 41 & 38.5 & 42 & $0.300^{* *}$ \\
\hline LDL-c mg/d1 & $124.66 \pm 39.89$ & $118.65 \pm 45.79$ & $126.63 \pm 37.97$ & $0.441^{*}$ \\
\hline TGmg/d1 & 153 & 148.5 & 153 & $0.747^{* *}$ \\
\hline GLUmg/d1 & 87 & 85 & 87 & $0.751^{* *}$ \\
\hline 1 pUlirn1 & 12 & 9.5 & 13 & $0.406^{* *}$ \\
\hline
\end{tabular}

\section{Discussion}

Cardiovascular disease is the leading cause of death in the world, as well as in Mexico, so timely detection and control of their risk factors is of great importance. In this analysis, CRFs found with the highest proportion were overweight and obesity, sedentaryism, abdominal obesity, hypertriglyceridemia, hypercholesterolemia and decreased $\mathrm{HDL}^{-\mathrm{c}}$ levels. Overweight and obesity are welldocumented risk factors for cardiovascular disease. The frequency found in this study was slightly higher (74.07\%), than the report in the National Mid-Way Health and Nutrition Survey 2016, ENSANUT MC 2016, in Mexico, that was (72.5\%). By sex, the prevalence observed in this study was $75.0 \%$ in women, similar to ENSANUT MC 2016 (75.6\%); however, the frequency observed in men in this study was $77.8 \%$, higher than the proportion found in the same national health survey, (69.4\%) [20]. It should be noted that, rather than being overweight or obese, it plays a transcendental role in the development of cardiovascular disease, abdominal obesity, as it deepens the metabolic effects such as insulin resistance, glucose intolerance, hypertriglyceridemia, low $\mathrm{HDL}^{-\mathrm{c}}$ levels among others. The proportion of abdominal obesity observed in this study was $55.56 \%$ in total population, and by sex, it was higher in females $(63.8 \%)$ than in men $(36.8 \%)$ with significant difference. ENSANUT MC 2016 reported abdominal obesity $76.6 \%$ in total subjects studied, $65.4 \%$ in men and $87.7 \%$ in women [20]. Although the proportion of subjects with abdominal obesity in this study was lower than ENSANUT MC 2016, when categorizing by sex, both studies were consistent with the higher prevalence of obesity in women with respect to men.

Other important study on cardiovascular risk factors in Mexican adult population, the "Lindavista Study", conducted by Meaney and collaborators, identified abdominal obesity as the most common cardiovascular risk factor (61\%), in the studied population 
[10]. The high proportion of overweight/obese individuals and specifically those observed with abdominal obesity could be related to inadequate eating habits and sedentary lifestyles, the latter reflected by the very low proportion of subjects who reported regular physical activity in this study, since in $74.07 \%$ of the individuals, sedentary lifestyle was identified; this percentage is higher than WHO estimation (60\%) of global inactivity [21]. Sedentary lifestyle that is devoid of traditional diets, which have been replaced by hypercaloric diets rich in saturated fats, trans fats and refined sugars, also promotes the presence of other important CRFs such as insulin resistance (IR) [22,23].

As for the frequency of alterations in biochemical parameters, this study found hypercholesterolemia $48.14 \%$, HDL ${ }^{-\mathrm{c}}$ levels $42.0 \%$, raised LDL cholesterol $39.5 \%$, triglycerides $50.6 \%$ and $38.27 \%$ of subjects with diabetes were identified; no significant gender differences were evident.

Meaney and collaborators in their Lindavista Study in Mexico refered to lower frequencies relative to this study in terms of hypercholesterolemia, 36\%, elevated levels of c-LDL, $25 \%$, hypertiglyceridemia $(41 \%)$. With regard to the proportion of subjects with low HDL cholesterol levels, the same authors obtained $42 \%$, coinciding with this research [10]. With respect to high blood pressure, the prevalence in Mexico, according to ENSANUT MC 2016 is $25.5 \%$, in men $24.9 \%$ and in women $26.1 \%$ [20]; what this study showed, $34.57 \%$ of total population, $25.0 \%$ of men and $37.1 \%$ of women, exceeded mexican national estimates. $100 \%$ of the patients included in this study showed at least one risk factor for cardiovascular diseases, it should be noted that a maximum of nine risk factors were observed in $2.5 \%$ of the population. It is known that the coexistence of several risk factors produces a synergistic effect that results in an increase in overall risk for CVD [24].

\section{Conclusion}

A high frequency of cardiovascular risk factors was observed in the community studied, and an elevated trend to associate among them, denoting the need to develop strategies to address these health problems opportunely in these communities.

\section{References}

1. Pérez LM, Herrera R, Villacís D, De León M, Fernández I W (2014) Obesidad pediátrica y factores de riesgo cardiometabólicos asociados. Rev Cubana Pediatr 86: 273-288.

2. (2019) WHO Enfermedades cardiovasculares. Cartas descriptivas.

3. Federación Internacional de Diabetes (IDF). Atlas. Sexta edición 2014.
4. Federación Mexicana De Diabetes AC (2016) Principales causas de mortalidad en México, INEGI Disponible.

5. Castro-Juárez CJ, Cabrera-Pivaral CE, Ramírez-García SA, García-Sierra L, Moralesc C Pérez L, et al. (2017) Factores de riesgo cardiovascular en adultos mexicanos. Revista MD 9(2): 152-162.

6. Gómez LA (2011) Las enfermedades cardiovasculares: un problema de salud pública y un reto global. Biomédica 31(4).

7. Pereira-Rodríguez J, Peñaranda-Florez D, Reyes-Saenz A, CaceresArevalo K, Cañizarez-Pérez Y (2015) Prevalence of cardiovascular risk factors in Latin America: a review of the published evidence 2010-2015. Revista Mexicana de Cardiología 26(3): 126-139.

8. Escobedo J, Pérez RJ, Schargrodsky H, Champgne B (2014) Prevalencia de dislipidemias en la ciudad de México y su asociación con otros factores de rieago cardiovascular. Resultados del estudio CARMELA. Gaceta Médica de México 150: 128- 136

9. Meaney A, Ceballos G, Gutiérrez G, Samaniego V, Alcocer L (2013) Investigación Clínica factores de riesgo cardiovascular en una pobación urbana de clase media mexicana. El estudio de Lindavista. Datos de referencia. Archivos de Cardiología de México 83: 42-67.

10. Sefiplan (2016) Gobierno del estado de Veracruz. Sistema de información municipal. Cuadernillos municipales.

11. Secretaría de Salud (2002) México: Por la Prevención de la Diabetes. Manual de procedimientos. Toma de Medidas Clínicas y Antropométricas En el Adulto y Adulto Mayor.

12. Friedewald WT, Levy RI, Fredrickson DS (1972) Estimation of the concentration of low-density lipoprotein cholesterol in plasma, without use of the preparative ultracentrifuge. Clin Chem 18: 499-502.

13. Araya V, Garrido M, Caamaño E, Romero C, Poniachik JY (2017) Evaluación de parámetros clínicos y de laboratorio relacionados con el diagnóstico de insulino resistencia. Rev chil endocrinol Diabetes 10(2): 53-58.

14. ATP III Guidelines At-A-Glance.

15. (2019) WHO. Sobrepeso Y Obesidad. Cartas descriptivas.

16. (2019) WHO. Sedentarismo. Cartas descriptivas.

17. Convenio Marco de la (2019) OMS para el control del Tabaco 2005-2015.

18. (2017) Standards of Medical Care in Diabetes-2017 Abridged for Primary Care Providers. American Diabetes Association, Clinical Diabetes 35(1): 5-26.

19. (2016) Encuesta Nacional de Salud y Nutrición de Medio Camino 2016. ENSANUT MC 2016.

20. WHO (2019) Inactividad física: un problema de salud pública mundial.

21. Barria RM, Amigo H (2016) Transición Nutricional: Una revisión del perfil Latinoamericano. ALAN 56(1): 3-11.

22. De Fronzo RA (1991) Insulin resistance. A multifactorial síndrome. Diabetes Care 36: 429-451

23. Yusuf HR, Giles WH, Croft JB, Anda RF, Casper ML (1998) Impact of multiple risk factor profiles on determining cardiovascular disease risk. Prev Med 27(1): 1-9. 
(CC) (i) This work is licensed under Creative (C) Commons Attribution 4.0 License

To Submit Your Article Click Here: Submit Article

DOI: 10.32474/LOJPCR.2020.01.000125

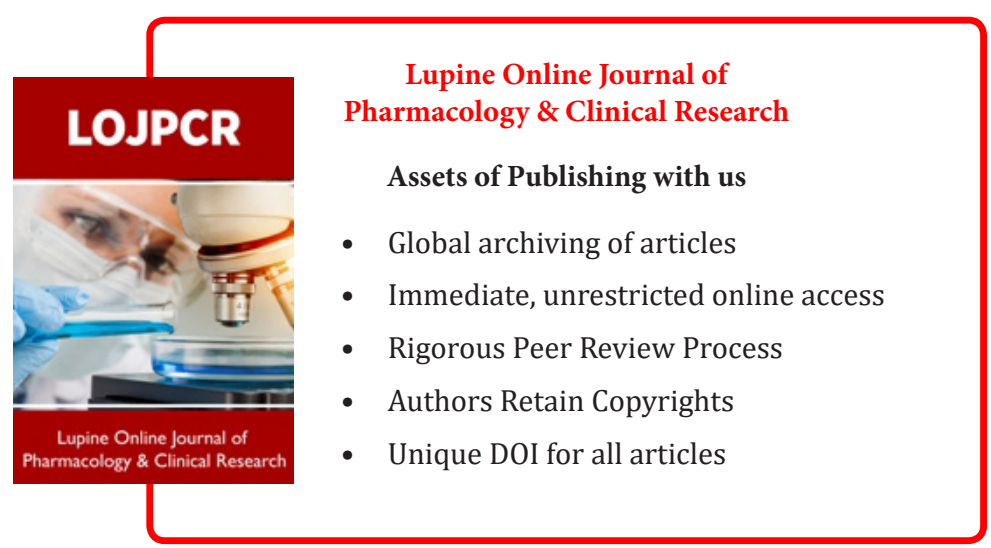

